\title{
TELEOST B CELL-ACTIVATING FACTOR (BAFF) DIFERENTIALLY REGULATES B CELL ACTIVITY IN LYMPHOID AND MUCOSAL TISSUES
}

\author{
Aitor G. Granja ${ }^{\S}$, Rosario Castro, Lucia González, Irene Soleto, Carolina Tafalla
}

Centro de Investigación en Sanidad Animal (CISA-INIA) Madrid 28130, Spain

\begin{abstract}
In mammals, B cell activating factor (BAFF) is a cytokine belonging to the tumor necrosis factor (TNF) family mainly produced by innate immune cells, such as macrophages and dendritic cells, to orchestrate early $\mathrm{T}$-independent $\mathrm{B}$ cell responses before $\mathrm{T}$-dependent follicular responses are mounted. Mammalian BAFF can signal through three different receptors: $\mathrm{B}$ cell maturation antigen (BCMA), transmembrane activator and calcium modulator and cyclophilin ligand interactor (TACI) and BAFF receptor (BAFF-R). In this context, we have undertaken an exhaustive characterization of the effects of BAFF on rainbow trout (Oncorhynchus mykiss) B cells, since understanding how BAFF regulates B cell responses is of high importance in teleost fish lacking lymphoid follicles. Here, we show that recombinant rainbow trout BAFF strongly promoted the survival of resting unstimulated $\mathrm{B}$ cells in vitro without inducing B cell proliferation. In addition, rainbow trout BAFF modulated the levels of membrane MHC class II on B cells as well as the expression of class II-associated genes and immunoglobulins, significantly altering their phenotype. Interestingly, the effects that BAFF produced on B cells were significantly different on B cells from central lymphoid organs (spleen) or mucosal tissues (gills), suggesting the involvement of different BAFF receptors according to the location of B cells. Unravelling the mechanisms underlying the effect of teleost $\mathrm{BAFF}$ on $\mathrm{B}$ cell differentiation will be of great importance to understand $\mathrm{T}$ cell-independent responses and to generate effective adjuvants in future vaccination strategies.
\end{abstract}

\section{KEYWORDS}

B cells / BAFF / MHC II / Trout / T cell-independent responses

§ Corresponding author. Tel +34 916202300; Fax +34 916202247.

Email address: aitor.gonzalez@inia.es 